Faculdade de Ciências Econômicas UFRGS
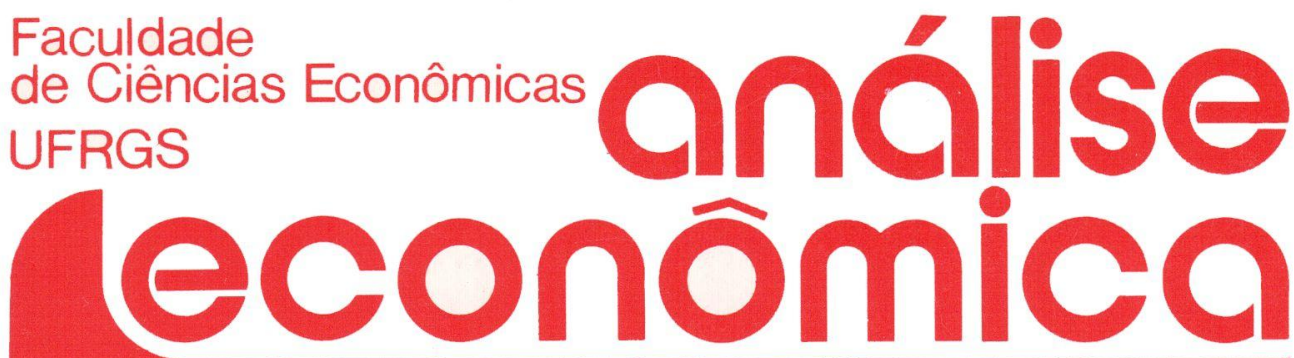

- A LINEAR MOdEL Of BALANCEd GROWTH Joanilio Rodolpho Teixeira Rodrigo Andrés de Souza Penaloza

- TEORIAS ESTRUTURALISTAS DA INFLAÇÃO

Roberto Camps Moraes

- PREÇOS EXTERNOS E EXPÓRTAÇÃO DE MANUFATURADOS Lauro Lobo Burle

- O DESENVOLVIMENTO SUECO Alfredo Marcolin Peringer

- DÉFICIT ENERGÉTICO Fabiano Augusto Nogueira Pinto

- RICARDO E O PROBLEMA SOCIAL Cezar Machado Mello

- UM SABER QUE NÃo SABE: INSTRUMENTO DE PREVISÃO Eleutério F.S. Prado

- SELEÇÃo dE PLANOS DE PRODUÇÃO PARA PEQUENOS PRODUTORES AGRICOLAS Juvir Luiz Mattuella

- PERSPECTIVAS da ECONOMIA do NORDESTE NA DÉCADA DE NOVENTA

Liana Maria da Frota Carleial

- CAIO PRADO JÚNIOR

Pedro Cezar Dutra Fonseca 
UNIVERSIDADE FEDERAL DO RIO GRANDE DO SUL Reitor. Prof. Tuiskon Dick

FACULDADE DE CIÊNCIAS ECONÔMICAS

Diretor: Prof. Walter Meucci Nique

CENTRO DE ESTUDOS E PESQUISAS ECONÔMICAS

Diretor: Reinaldo lgnácio Adams

DEPARTAMENTO DE CIÉNCIAS ECONÔMICAS

Chefe: Prof. Pedro Cezar Dutra Fonseca

CURSO DE PÓS-GRADUAÇÃO EM ECONOMIA

Coordenador: Prof. Nali de Jesus de Souza

CURSO DE PÓS-GRADUAÇĀO EM ECONOMIA RURAL

Coordenador. Prof. Atos Freitas Grawunder

CONSELHO EDITORIAL: Achyles Barcelos da Costa, Aray Miguel Feldens, Atos Freitas Grawunder, Carlos Augusto Crusius, Ernani Hickmann, João Rogério Sanson, Juvir Luiz Mattuella, Maria Imilda da Costa e Silva, Nali de Jesus de Souza, Nuno Renan Lopes de Figueiredo Pinto, Otília Beatriz Kroeff Carrion, Otto Guilherme Konzen, Paulo Alexandre Spohr, Pedro Cezar Dutra Fonseca, Reinaldo Ignacio Adams, Roberto Camps Moraes, Valter José Stülp, Yeda Rorato Crusius, David Garlow (Wharton Econometrics Forecasts Association, E.U.A.), Edgar Augusto Lanzer (UFSC), Eleutério F.S. Prado (USP), Fernando Holanda Barbosa (FGV/RJ), Gustavo Franco (PUC/RJ), Joaquim Pinto de Andrade (UnB), Juan H. Moldau (USP), Werner Baer (Univ. de Illinois, E.U.A.).

COMISSĀO EDITORIAL: Atos Freitas Grawunder, Pedro Cezar Dutra Fonseca, Reinaldo Ignacio Adams e Roberto Camps Moraes.

EDITOR: Nali de Jesus de Souza

SECRETARIA: Maria Ivone de Mello (normalização), Vanete Ricacheski (revisão de textos), Zélide Bregalda (Secretária).

FUNDADOR: Prof. Antônio Carlos Santos Rosa

Os materiais publicados na revista Análise Econômica são de exclusiva responsabilidade dos autores. É permitida a reprodução total ou parcial dos trabalhos, desde que seja citada a fonte.

Aceita-se permuta com revistas congêneres. Aceitam-se, também, livros para divulgação, elaboração de resenhas ou recensōes.

Toda correspondência, material para publicação, assinaturas e permutas devem ser dirigidos ao seguinte destinatário:

PROF. NALI DE JESUS DE SOUZA

Revista Análise Econômica

Av. João Pessoa, 52

90.040 - PORTO ALEGRE (RS), BRASIL

Telefone: (0512) 25-58-44 ramal 33

Fax: (0512) 25-5253 


\title{
DÉFICIT ENERGÉTICO
}

\section{Fabiano Augusto Castro Nogueira Pinto*}

\begin{abstract}
SINOPSE
O modelo energético é posto em questão a partir dos choques do petróleo. Com a profunda alteração da polf́tica internacional em relação ao crédito, outra importante fonte energética, a hidreletricidade também passa a ter problemas. A reformulação da política energética faz-se necessária para a saida da crise em que o Pals se encontra desde fins dos anos setenta. Assim, propõe-se neste trabalho uma revisão de pontos especfficos da politica energética do País. Dentre esses pontos destacam-se a questão da eficiência do uso da energia, os investimentos no setor, as "tarifas" e a regionalização e integração energética.
\end{abstract}

\section{INTRODUÇÃO}

As crises energéticas, nas décadas de setenta e oitenta, fizeram aflorar diversos problemas a serem enfrentados, para o Brasil continuar crescendo. $O$ déficit energético ocorreu em razão das crises energéticas, que, por sua vez, foram decorrentes de outros fatores.

No início da década de oitenta, houve dificuldades para dar seguimento aos diversos projetos iniciados na década anterior, ocasionando, no que concerne à energia, um profundo abalo no setor energético, fruto da incoerente política econômica então vigente.

Em 1990, enfrenta-se uma situação calamitosa no setor energéti$\mathrm{co}$, que se pode constatar como resultante do desajuste ocorrido na politica energética, nos anos setenta e oitenta, tanto no plano institucional,

* Da FCE/UFRGS. O autor agradece à Professora Yeda Rorato Crusius, do Curso de Pós-Graduação em Economia da UFRGS, pelos comentários efetuados a este trabalho.

ANÁLISE ECONO̊MICA

ANO $8 \quad$ № 14

NOVEMBRO/90

p.69-95 
qūanto no prático.

Mas, para este estudo ser formulado, é necessário a análise de alguns fatores, que levará à melhor compreensão do problema.

Inicialmente será feita a apresentação e classificação do produto energia, ou seja, como este se enquadra nas discussões econômicas.

Como produto, a energia tem seu mercado. Assim, serão caracterizados o cenário institucional e seu comportamento, contrastando os mercados aberto e fechado com a eficiência do uso da energia. A partir deste cenário institucional, chegar-se-á ao modelo de oferta de energia, desde a questão formal de ofertar, até a caracterização do aspecto politico da produção/geração e venda da mesma. A oferta, em contraste com sua demanda, em função de diferentes aspectos, os quais serão analisados posteriormente, dará subsídios para que se entenda o porquê e como ocorreu a crise energética.

Esta será apresentada inicialmente pelos dois choques de preços do petróleo, os quais desencadearão o "trade-off" entre algumas fontes energéticas. Isto, por sua vez, forçará a um aumento progressivo dos investimentos no setor energético, dada a opção escolhida na época, correspondente ao segundo qüinqüênio da década de setenta. Esses investimentos levarão a um endividamento cumulativo, que se tornará insustentável no inicio da década de oitenta, levando o Governo brasileiro a redirecionar a política de energia, o que acabará por ocasionar um déficit energético, agravado pelo uso não-racional de energia.

Para explicar essa incoerência, é apresentada a questão tarifária. Nesse caso, deve ser referida a necessidade de estruturação do mercado e de suas políticas de oferta que, através de tarifas irreais e aviltadas, estimulam o uso desordenado de determinada fonte energética. A tarifa, além de ser um fator de remuneração e capitalização dos serviços prestados pelo setor, promove a ampliação da capacidade do mesmo.

A co-geração e autogeração são questões especificamente institucionais que, por meio de políticas tarifárias corretas e de adequada abordagem dos aspectos legais e ideológicos, espera-se poder levar à solução do problema.

Este trabalho tem, pois, como objetivo apresentar o déficit energético como decorrência de uma questão institucional, tratando a energia como um vetor e não como um insumo, ao mesmo tempo em que procura, à luz da crise energética, identificar os problemas que ocasionaram o déficit energético, situação que está gerando uma forte perspectiva de racionamento. A partir do estudo destes problemas, chega-se à 
crítica do modelo energético atual, sem que se prive de fazer alusões a possiveis soluções.

\section{APRESENTAÇÃO E CLASSIFICAÇÃO DO "PRODUTO ENER- GIA"}

Energia é um recurso natural, utilizado como produto intermediário na geração de bens e no consumo final, instrumento de um padrāo de vida moderno (consumo residencial, por exemplo).

Como estratégia de desenvolvimento econômico, a energia deve: 1) satisfazer às necessidades humanas básicas, como saúde, habitação, educação, alimentação, etc.; 2) servir às atividades industriais que geram emprego; 3) sustentar as atividades agrícolas que produzem alimentos. Quanto à segunda afirmação, dependendo do segmento de atividade econômica, o consumo de $1 \mathrm{GWh}$ implica o emprego de $X$ trabaIhadores. Para ilustrar esta situação, a tabela 1 apresenta dados de três setores industriais e três paises.

TABELA 1

NÚMERO DE EMPREGOS GERADOS POR CONSUMO DE ENERGIA ELETRICA EM GWh (1979)

\begin{tabular}{lccc}
\hline INDÚSTRIAS & USA & FRANÇA & ITÁLIA \\
\hline $\begin{array}{l}\text { Papel, papelão e } \\
\text { celulose }\end{array}$ & 21,5 & 52,2 & 29,2 \\
$\begin{array}{l}\text { Têxteis, confecções e } \\
\text { prod. de couro }\end{array}$ & 69,1 & 76,9 & 92,6 \\
$\begin{array}{l}\text { Metais básicos (aço, } \\
\text { ferro e não-ferrosos) }\end{array}$ & 6,1 & 14,6 & 11,9
\end{tabular}

FONTE: FACT BOOK - Production and Consumption of Eletricity, apud RAMOS (1989, p.14). 
O uso da energia nas atividades agrícolas diz respeito à questão da modernização da produção agrícola, alternativa imprescindível para aumentar a produção e a produtividade agrícola (alimentos). Para isso, há necessidade de energia adicional para arados mecânicos, tratores, bombas de irrigação e produção de fertilizantes que, somado ao capital e outros insumos, não substituiria, necessariamente, a mão-de-obra a fim de aumentar a produção, o que dependeria da combinação de tecnologias utilizadas. Há, porém, outro aspecto que é a produção agrícola com geração de energia (bioenergéticos/biomassa) e, portanto, a competição entre produção de alimentos e energia na agricultura.'

Quanto às necessidades humanas básicas, pode-se afirmar que a alimentação diz respeito à necessidade de calorias diárias (per capita) a serem consumidas. Como apontou Goldemberg (1988, p.38), o atendimento de cada necessidade humana demanda energia.

O quadro 1 mostra como classificam-se as fontes primárias de energia (existem, porém, outras formas de classificação), que utilizar-seá neste trabalho.

O fato das fontes não-renováveis de energia serem finitas preocupa os segmentos econômicos direta ou indiretamente envolvidos. Tem havido um profundo redirecionamento da politica energética que, até então, vinha sendo seguida, gerando o "efeito-substituição" (Giambiagi, 1985, p.387). Este se traduz na preferência por outra fonte energética, em detrimento da habitualmente usada. No caso específico do Brasil, este "trade-off" entre energia primária não-renovável e energia primária renovável se traduz no declínio do consumo de petróleo e no aumento do uso da eletricidade, face ao grande potencial hídrico do País. Seguindo esta ótica do consumo, as fontes primárias não-renováveis somavam, em $1973,45,9 \%$ e as renováveis, $54,1 \%$. Em 1986, com a nova politica energética, o consumo das fontes primárias renováveis aumentou para $59,6 \%$ enquanto as não-renováveis diminuíram para $40,4 \%{ }^{2}$

1 Ver, a respeito desse conflito, Melo \& Pelin (1984) ou Feldens \& Larson (1988).

2 Neste parâmetro traçado entre fontes primárias renováveis e năo-renováveis, foram somadas entre as renováveis: energia hidráulica, lenha, cana-de-açúcar e outras (reslduos vegetais e industriais para geração de calor); e não renováveis: petróleo (inclusive o excedente derivado exportado), gás natural, carvão, vapor e carvão metalúrgico (dados disponlveis no Brasil (1987, p.11, tab.13). 


\section{QUADRO 1}

\section{CLASSIFICAÇĀO DAS FONTES PRIMÁRIAS DE ENERGIA}

* Fontes Não-Renováveis (combustíveis fósseis):

- Gasosos (gás natural)

- Líquidos (óleo cru, óleos pesados, areias betuminosas, folheIhos betuminosos)

- Sólidos (turfa, hulha, xisto)

* Fontes Não-Renováveis:

- Gravitacional (energia das marés)

- Nuclear (combustiveis nucleares)

- Geotérmicas (calor de baixa e alta entalpia)

* Fontes Renováveis:

- Hidráulica

- Biomassa

- Eólica (vento e onda)

- Solar Direta

- Calor dos Oceanos e Lagos (OTEC - Ocean Thermal Energy Conversion)

FONTE: Revisão Institucional do Setor Energético / CEEE. Vol.ill A (5/12/1986).

A oferta de energia condiciona a demanda pela mesma que, conseqüentemente, limita a atividade econômica. Segundo Chacel (1989) as projeções de demanda energética superestimam as condições de oferta de energia.

As estruturas econômicas brasileiras apresentam-se ineficientes em termos energéticos; outros paises, mesmo os em desenvolvimento, têm uma intensidade energética muito inferior à brasileira. ${ }^{3}$

Dados do Banco Mundial (1982) revelam que, entre 1973 e 1986, nos Estados Unidos, o consumo de energia manteve-se estável e seu PIB aumentou $36 \%$. Sua intensidade energética melhorou $2,4 \%$ ao ano, no período. $O$ Chile e a Costa Rica, apesar de serem subdesenvolvidos, são países de economia aberta no que diz respeito ao uso racional de

3 Intensidade energética $=$ consumo de energia/unidade do $\mathrm{PIB}$. 
energia (Hukai, 1989), tendo, assim, desempenhos energéticos superiores aos das economias fechadas, como é o caso da brasileira.

\section{1 - Mercados}

Os setores de energia elétrica e de petróleo, no Brasil, evoluíram de um modelo empresarial aberto, com a participação de capital estran. geiro, para um modelo fechado, onde a União controla a oferta.

Este modelo estratégico é caracterizado pela manutenção da empresa estatal única de petróleo e de um número limitado de organizações estatais de âmbito nacional, regional e estadual no setor elétrico, pela centralização das decisões e pela prática de preços e tarifas equalizados, enfatizando efeitos sócio-econômicos globais.

Os demais setores (carvão vegetal, lenha e outras biomassas) praticam o mesmo modelo empresarial de antes, caracterizado por maior diversidade de fornecedores, descentralização institucional e regional, prática de preços aderentes aos custos.

A razão que pareceu existir, impulsionando o crescimento nas décadas de cinqüenta e sessenta nos setores elétrico e de petróleo, residiu na decisão do Governo brasileiro de crescer de modo acelerado. $O$ fornecimento de energia elétrica era o vetor para o desenvolvimento industrial e os combustíveis líquidos eram fundamentais para o desenvolvimento do setor de transportes. Esta rapidez conduziu, naturalmente, à escolha de estruturas com maior facilidade de intervenção estatal, considerando a soberania na gestão dos recursos naturais do País, podendo-se, assim, observar a importância estratégica destes dois setores.

$O$ tratamento da oferta de energia é setorial, com estruturas quase completamente independentes para cada setor, praticamente sem organismos de integração. O petróleo, o álcool e o carvão mineral estão sob a égide do Conselho Nacional do Petróleo (CNP).

O setor elétrico é controlado pela Eletrobrás. Quanto aos demais setores, não tão representativos na matriz energética ${ }^{5}$, ficam aos cuida-

\footnotetext{
4 Segundo matéria publicada pela revista Comércio e Mercados (ago. 1981), no passado havia intensa participação do capital privado nacional e estrangeiro. A partir de 1934 (ano de instituição do Código das Águas), o setor de energia elétrica ficou sob a orientação da União, que autorizava o aproveitamento de energia elétrica para uso público, restrito a empresas organizadas no Pais. Em 1961, foi criada a ELETROBRÁS, consolidando a política eletroenergética nacional, ao assumir o planejamento e coordenação da polftica de energia elétrica.

5 Entende-se por matriz energética o fluxo energético relativo ao conjunto de fontes energéticas empregadas no processo produtivo de um pals.
} 
dos, porém de forma menos ustensiva, de órgãos, como o Ministério da Agricultura, no caso da Bioenergia (biomassa). Entretanto, não parece existir mecanismos superiores de integração de todos estes setores.

É certo que a prática do modelo estritamente setorial levou a sucessos, mas conduziu a desvios não esperados, os quais obscureceram a transparência das decisões e os mecanismos de acompanhamento, avaliação e controle.

Dentre os esforços de planejamento integrado realizados no passado, cabe destacar a Matriz Energética Brasileira (1970-1973), o Balanço Energético Projetado (1976-1978) e o Modelo Energético Brasileiro (1979-1981) que não resultaram na fixação de procedimentos de revisão e formulação de diretrizes de poítica energética e de planos integrados para o setor.

A Comissão Nacional de Energia (CNE), que, desde 1979, apresentou um passo à frente no tratamento das diferentes fontes de oferta de energia, conjuntamente com setores de demanda e de regulação, até hoje, mesmo priorizando esta integração em conseqüência da estruturação fortemente setorializada, tem tido grandes dificuldades na reorientaçẳo da oferta de energia.

Hoje, o próprio mercado condena o modelo estruturado anteriormente, como sendo ineficiente, devido à defasagem que se estima entre a demanda e a crescente necessidade para um futuro próximo da capacidade de ofertar. Também as perspectivas mundiais demonstram uma forte tendência rumo a mercados cada vez mais competitivos, exigindo redução dos custos e ganhos em qualidade, além da integração continental, em que dois ou mais paises possam participar de um mesmo projeto de oferta e demanda de uma mesma fonte energética. Essa tendência se constata hoje na Europa, América do Norte é no Oriente, ou até mesmo na América Latina, como no caso de Itaipu e a compra de gás natural da Bolivia por parte do Brasil.

A transição institucional esbarra num problema de organização de mercado, pois como as estruturas são diferentes, conforme o setor, as empresas têm que se dirigirem a órgãos diversos e praticar procedimentos diferentes, pois se alguns setores estão sujeitos às regras administrativas pela União, outros praticam regras de mercado (ex.: biomassa, exceto cana-de-açúcar).

Quanto à competição entre energéticos, vive-se hoje, no Brasil, a discussão pública a respeito do álcool carburante e a gasolina, em que os usuários sentem-se enganados pela União, uma vez que esta, apesar 
de administrar os preços, não manteve a confiabilidade do sistema, em razão de ter-se descuidado do abastecimento, devido a problemas entre produtores de cana-de-açúcar, destilarias e Governo, quanto à fixação de preços. À União caberia um maior cuidado no seu relacionamento com 0 consumidor, sinalizando para a sociedade uma visão estável desse mercado para o médio e o longo prazo.

\subsection{1 - Oferta}

A oferta de energia consiste, basicamente, em três etapas, que são: geração, transmissão e distribuição. Por geração, pode-se entender a extração, no caso dos minérios e, em alguns casos, a transformação, como no refino do petróleo, ou seja, a produção primária de energia. A transmissão é muito importante no processo de determinação da oferta, para que não aconteçam perdas significativas de energia, tais como vazamentos em oleodutos ou fios de cobre condutores.

A etapa de distribuição deve atender às necessidades dos mercados, de forma que não haja problemas na atividade econômica, decorrentes da má distribuição dos produtos energéticos disponiveis. Nenhuma destas etapas é independente uma das outras, portanto deve haver um sincronismo, uma politica de oferta de energia.

Uma política de oferta de energia deve consistir em reunião de informações provenientes de atividade de transformação, prospecção, recursos e resenvas atuais e potenciais, avaliação técnica e econômica destas informações, projeções de demanda dos principais energéticos, à base de tendências históricas quando relacionadas a algumas correlações econômicas, além de dados específicos sobre projetos industriais de grandes consumidores de energia; tentativa de compatibilização dos resultados com projeções de demanda de energia, baseadas em taxas de evolução do PIB, estrutura do PIB, população e um coeficiente de variação da intensidade-produto do consumo de energia. ${ }^{6}$

Frente a isso, busca-se, hoje, uma forma de equacionar o problema da oferta de energia, uma vez que as empresas energéticas estão sem recursos para investimento, tornando-se dependentes do Estado.

As diversas fontes energéticas se caracterizam por problemas específicos de oferta energética, tais como:

- Petróleo: na década de setenta houve dois choques dos preços

5 Coeficiente de variação da intensidade - produto = variaçăo do consumo de energia/variação do PIB. 
internacionais desse produto, fazendo com que se procurassem fontes alternativas para o mesmo (ex.: álcool).

- Hidreletricidade: possui maior atratividade econômica, além de ser caracterizada como uma fonte energética limpa e renovável, mas há a necessidade de equacionamento de problemas ambientais, sociais, institucionais (estrutura e investimento), custos de transmissão a longa distância, etc.

- Gás natural: é usado especificamente em sistemas isolados ou em situações especificas de proximidade ao campo de produção; uso em processo de co-geração. Este produto, escasso no Brasil, e por ter custo elevado de extração, não se ajusta à substituição por energia elétrica, e sim por óleos combustíveis, principalmente nos horários de pico.

- Nuclear: opção em reestudo diante da necessidade de equacionamento de problemas ambientais, sociais e políticos. Foi uma das causas dos cortes e suspensões, feitos pelo Banco Mundial e BID, dos recursos contratados junto aos mesmos, em razão do repasse de verbas para a Nucleobrás.

- Biomassa: é usada em sistemas isolados de pequeno porte (caracteristicamente setorizado); ern razão disso, não forma uma estrutura, dificultando sua operacionalização, embora muitas vezes apresenta grandes vantagens (ex.: bagaço de cana).

0 gráfico 1 , a seguir, demonstra que a oferta interna de energia ${ }^{7}$

GRÁFICO 1 - COMPOSIÇÃO DA OFERTA INTERNA DE ENERGIA PRIMÁRIA

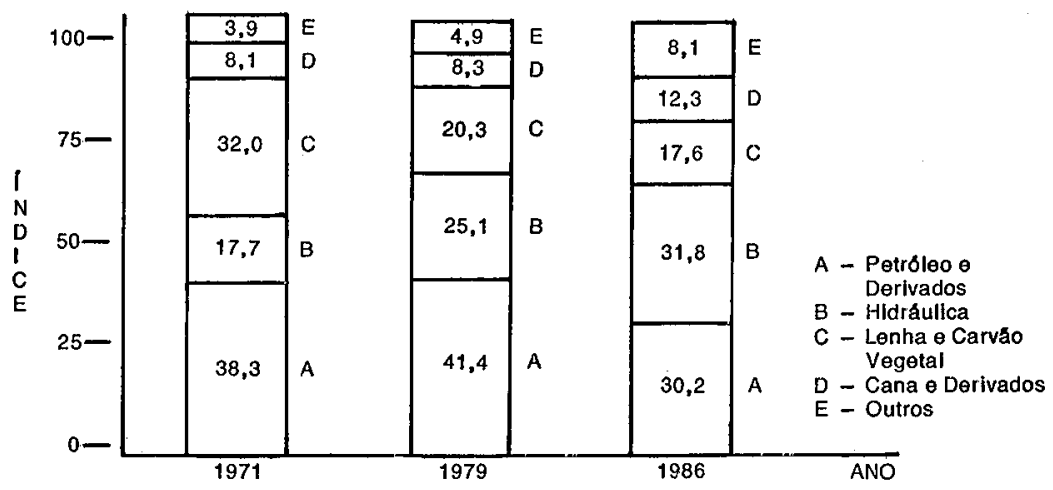

FONTE: Brasil, Balanço Energético Nactonal (1987, p.10)

7 Oferta Interna de Energia: é a energia efetivamente gasta no pals (consumo final + perdas na transformação, distribuição e armazenagem). 
sofreu profundas transformações, quanto ao efeito-substituição, em decorrência de diversos fatores, tais como: os dois sucessivos choques de preço do petróleo na década de setenta, os investimentos então feitos para geração de energia elétrica (limpa) de fonte hídrica e a busca de alternativas, como no pró-álcool onde a biomassa passa a ter maior participação por conta da cana-de-açúcar e de seus derivados.

Quanto à produção de energia, o Brasil tornou-se deficitário em eletricidade a partir de 1983, quando passou a importar em volume crescente, face ao maior consumo da mesma. Já quanto ao petróleo, depois de atingir o pico em 1979, o País reduziu as importações, em virtude dos altos preços praticados no mercado externo, investindo com sucesso na prospecção de novos poços de petróleo, chegando a produzir mais de $60 \%$ do seu consumo total, em $1986 .^{8}$

O grande problema, que a queda do investimento gerou, foi a limitação da quantidade de energia ofertada. Isso é extremamente danoso, uma vez que restringe a atividade econômica. Outra questão que se pode apontar é que cerca de $40 \%$ do consumo de energia elétrica é clandestino, face à existência de empresas do setor informal da economia, que não recolhem impostos, mas consomem energia. Tornam-se, portanto, cada vez mais escassos os recursos para investimento, a fim de gerar energia. O problema agrava-se quando os preços e/ou as tarifas são subsidiados por um espaço de tempo que, muitas vezes, torna-se excessivamente longo.

Só com uma política coerente pode-se chegar a um equacionamento do déficit energético. Para os anos noventa espera-se, pelo lado da oferta, e dado o quadro institucional: a) a expansão da rede de transmissão de energia; b) maiores investimentos nas obras em andamento; c) intensificação da produção de energia nas regiões onde haja maior capacidade instalada de consumo e produção.

\subsection{2 - Demanda}

Existem dois tipos de demanda de energia que podem ser empregados para estimar as necessidades energéticas de um pais: demanda energética setorial e demanda energética agregada. Para obter-se o primeiro tipo, estima-se o consumo de energia necessário aos diversos setores da economia (estudo de classe e estrutura de consumo energé-

8 Isto em termos líquidos, sem considerar as perdas na transformação, distribuição e armazenagem. 
tico), como transporte, comércio, agricultura, etc. Para a obtenção do segundo tipo, estima-se o consumo total de energia requerida pelo pais.

As variáveis que compõem a função demanda energética são: PIB (efetivo e esperado), preços e/ou tarifas dos produtos energéticos e tamantho da população. Estas variáveis comportam-se da seguinte forma:

- PIB efetivo: os países em desenvolvimento, como o Brasil, apresentam um consumo crescente de energia em relação ao PIB. Torna-se bastante ilustrativo o que os dois gráficos a seguir demonstram a respeito deste comportamento. Neles, vê-se que o crescimento do consumo de energia elétrica brasileiro é semelhante ao crescimento do PNB japonês (os dados japoneses são para o período de 1965-1985 e os brasileiros para 1970-1986). Isto ilustra, mais uma vez, a contraposição de uma economia fechada (Brasil) com outra onde o mercado é aberto (Japão). Cabe dizer que o PNB japonês apresentou um dos maiores aumentos dentre todos os países da OCED (Organization for Economic Cooperation and Development), neste periodo (Hukai e Christodoulou, 1989.

GRÁFICO 2 - EVOLUÇÃO DO PIB E CONSUMO DE ELETRICIDADE NO JAPÃO (1965-1985)

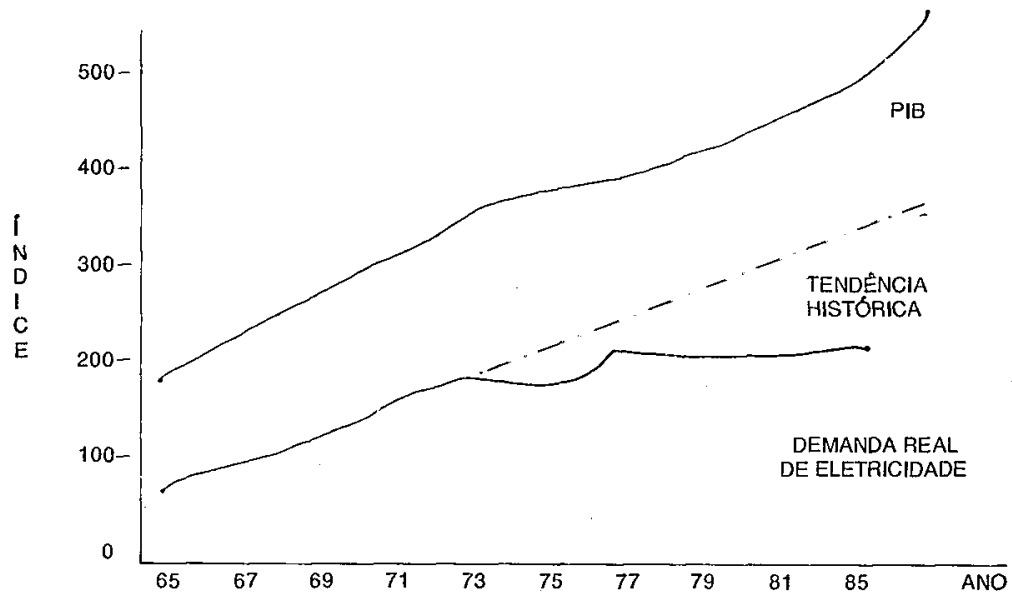

FONTE: HUKAI @ CHRISTODOULOU (1989) 


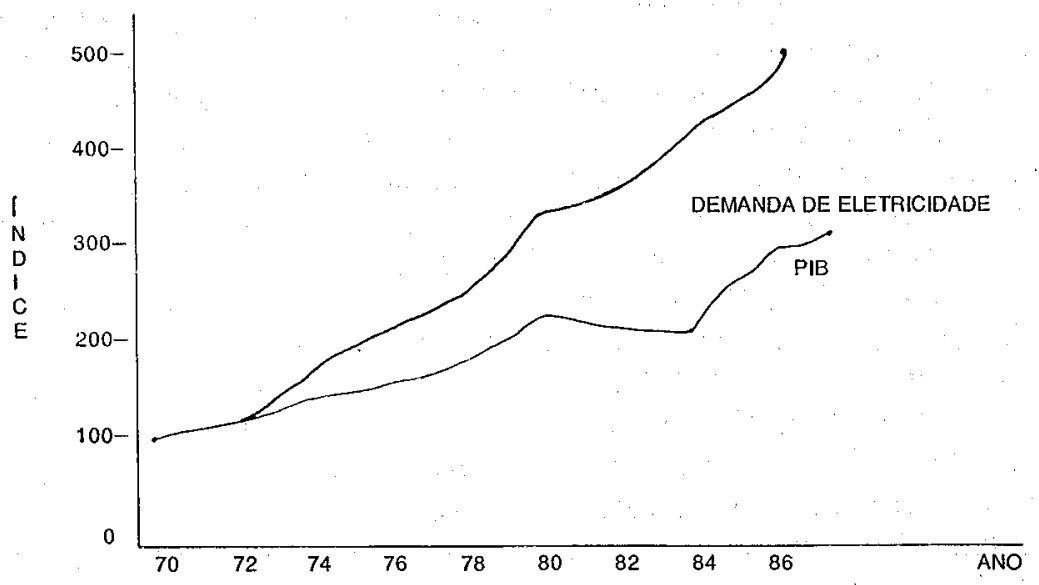

FONTE: HUKAI \& CHRISTODOULOU (1989).

Especificamente, o que se pode falar do Brasil, é que seu PIB comportou-se de forma crescente durante toda a década de setenta. Mesmo com o primeiro choque de preços do petróleo, em 1973, observou-se a continuidade do crescimento econômico, em muito devido ao efeito substituição, ocorrido posteriormente.

A hidreletricidade apresentou-se como uma fonte bastante atrativa, dentro do espírito empreendedor das autoridades, da época, e face às facilidades creditícias que o mercado internacional apresentava.

Este "trade-off" foi de vital importância, caso contrário ${ }^{9}$ o periodo subseqüente à elevação do preço do petróleo teria sido de profunda estagnação. Mas com o segundo choque do petróleo a situação agravouse, pois até mesmo o mercado internacional se ressentiu e não mais apresentou as mesmas condições anteriores, propícias aos vultosos investimentos. Segundo Gimbiagi (1985, p.405), "Além da condenação prescrita pelo FMl", que foi "(...) o endividamento com recessão (...). A situação atual dos paises endividados, dentre os quais o Brasil, se destaca por ter realizado um ambicioso programa de investimento depois de 1973 e ser hoje aquele que detém as melhores perspectivas de cresci-

9 Isto significa: sem alteração da base energética. 
mento, demonstra que a recusa então feita à recessão como íorma de equacionar a crise externa revelou-se posteriormente positiva". Contudo, após 1980, esta perspectiva descrita por Gimbiagi não se confirmou, face à ampliação da crise.

Mesmo assim, um novo desafio foi assumido pelo Governo, que foi o Pró-álcool. Esse projeto visa a substituição, principalmente, de gasolina por álcool, mas consegue atingir quase que somente os veículos de pequeno porte.

Mas, efetivamente, isto não alterou a situação energética de forma muito profunda, uma vez que, no início da década de oitenta, o Brasil enfrentou um período (1980-1983) de estagnação (cf. o gráfico 3), quando observou-se que os únicos energéticos que tiveram consumo decrescente, nesse mesmo período, foram os derivados de petróleo, enquanto outros energéticos (álcool etílico, bagaço de cana e eletricidade) tiveram seu consumo crescente (Brasil, 1987, e gráfico 2).

- PIB esperado: a partir desta variável, pode-se projetar a demanda energética futura, desde que se considere as possiveis mudanças da matriz energética. Quanto às alteraçōes do PIB esperado, mantidos os mesmos coeficientes de variação da intensidade-produto, podese estimar a parte de demanda futura, explicada por este índice de desempenho da economia.

- Preços e/ou tarifas dos energéticos: embora esteja-se comentando a demanda agregada, esta discussão deve ser setorizada, pois comporta-se de diferentes formas, segundo os distintos produtos energéticos.

Os derivados de petróleo têm seus preços controlados pelo Conselho Nacional do Petróleo (CNP), órgão do Ministério das Minas e Energia que, conjuntamente com o Ministério da Fazenda, determinam o preço. Certamente a evolução dos seus preços tem-se demonstrado bem mais realista, comparativamente a outros energéticos, o que deriva um consumo (médio) decrescente, dos derivados de petróleo, como prova o gráfico a seguir. 
GRÁFICO 4 - EVOLUÇÃO DO PREÇO REAL E CONSUMO DE GASOLINA POR VEICULL ATIVO (1973-1985).

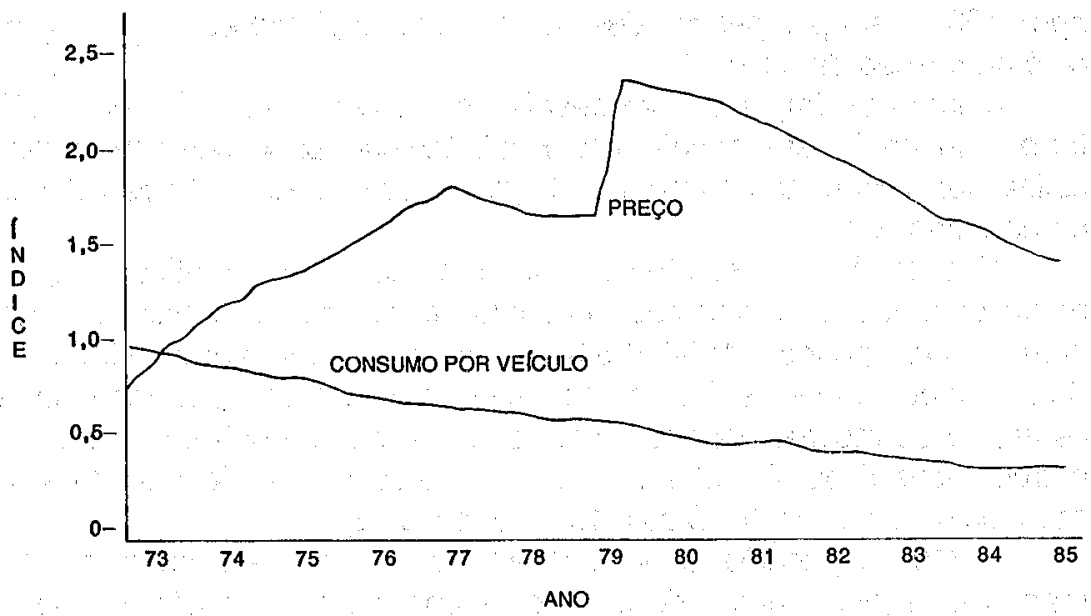

FONTE: HUKAL $\Theta$ CHRISTODOULOU (1989).

Segundo o gráfico 4, verifica-se que a redução do consumo de derivados ocorreu justamente quando houve aumentos reais de seus preços, em função dos dois choques do preço internacional do petróleo.

O gráfico 5, a seguir, mostra as conseqüências da política tarifária em relação a energia elétrica, cujos valores foram contidos, em termos reais, a fim de "conter" o processo inflacionário. Isso gerou uma brutal defasagem, dificultando a realização dos investimentos necessários para o complexo processo de geração, transmissão e distribuição de energia elétrica projetado para o Brasil. $^{9}$ 
GRÁFICO 5 - EVOLUÇÃO DO PREÇO REAL E CONSUMO DE ELETRICIDADE POR UNIDADE RESIDENCIAL (1973-1987)

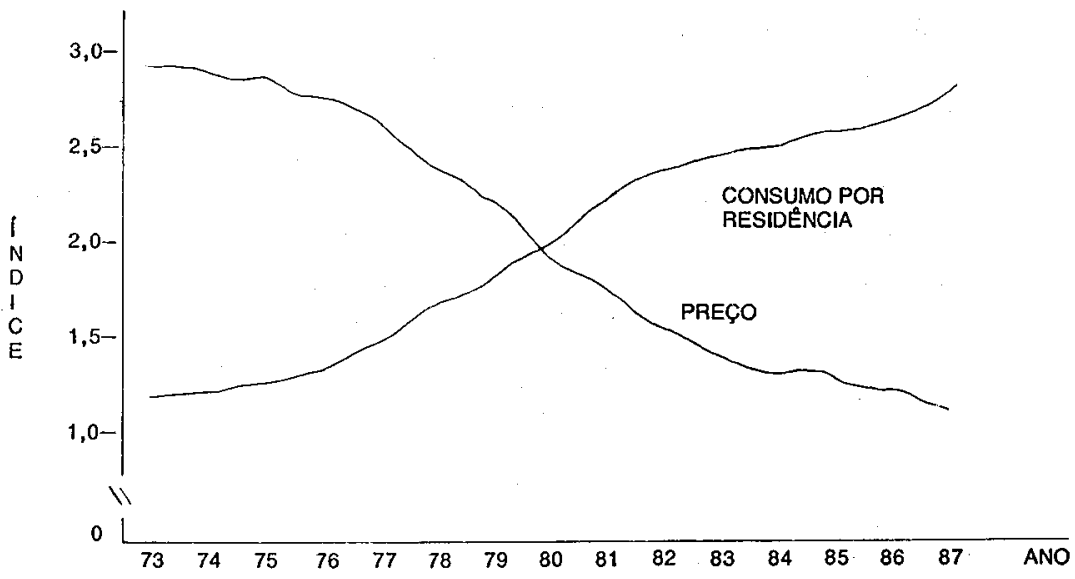

FONTE: HUKAI $\theta$ CHRISTODOULOU (1989).

Devido a esta defasagem tarifária da energia elétrica, segue-se outro grande problema que é o uso não racional deste energético, ou seja, justamente por não reprešentar grandes custos para seus usuários há um consumo abusivo do mesmo. Existem estimativas da possibilidade de poupar (efeito conservação) grandes quantidades de unidades consumidas de energia elétrica, caso seja eliminado este consumo supérfluo sem que o PIB ou a Matriz Energética sejam afetados. ${ }^{10}$

Os preços praticados no caso do álcool etílico, ${ }^{11}$ pondérados pela vigência das portarias do CNP, têm-se mostrado estáveis, em termos reais, ao passo que sua demanda tem crescido desde a implantação do projeto Pró-álcool, por razões que não cabe aqui discutir.

No cômputo geral, pode-se inferir que a demanda energética tem crescido, de acordo com os componentes de demanda supracitados, exigindo, paralelamente, ao crescimento da população, o aumento da geração de energia.

10 Para discussão mais profunda ver estudo da PROCEL (1988), realizado com base em 900 diagnósticos realizados em indústrias pela COPEL, CEMIG, CPFL, ELETROPAULO, CESP, CEEE, CELESC, COELBA, ESCELSA e CEB.

11 Contém álcool anidro e hidratado. 


\section{CRISE ENERGÉTICA}

É muito difícil, ou quase impossivel não relacionar o ocorrido no setor energético brasileiro na década de oitenta com a crise econômica pela qual o Brasil passou neste mesmo periodo.

Segundo Castro (1985, p.7), a crise estendeu-se de 1981 a 1984, e parecia caminhar para um colapso. Esta mesma crise desfez os sonhos do "Brasil-potência", colocando-o diante do crescimento do desemprego aberto e da hipótese de sucateamento da indústria.

Basicamente três aspectos contribuíram, neste período, para a crise do setor energético: a) o aumento desproporcional da demanda em relação à oferta de energia, o que gerou um desajuste no sistema energético; b) ineficiência no uso da energia, que se traduz em desperdício; c) uso não coordenado dos instrumentos, a fim de estabelecer uma melhor política energética.

\section{1 - Os Choques do Petróleo}

Com o aumento dos preços internacionais do petróleo, em 1973, e com o estrangulamento cambial, pós-74, que pressionou uma política de exportação e restringiu as importações, o Brasil forçou-se a retomar a estratégia de substituição de importações. O resultado disso foi uma redução das importaçōes da ordem de 2,38\%, entre 1974 e 1976, mesmo com o crescimento médio anual da economia em $8,2 \%$, no mesmo período. A participação da importação de produtos manufaturados na oferta global caiu de 12,9\% em 1974, para 7,1\% em 1980.

Em 1974 e 1975, enquanto algumas economias, tais como os Estados Unidos, Alemanha, México, adotaram políticas de desaquecimento, a partir da elevação dos preços do petróleo, o governo brasileiro reiterou sua opção já usada nos anos sessenta, a do crescimento com endividamento (Castro, 1985, p.28), tendo como base os fundos disponiveis nos bancos estrangeiros procedentes da OPEP, a concessão do crédito dava-se sem maiores restrições.

Em 1979, o País é atingido novamente por novo choque do petróleo. Este fato, somado às altas taxas de juros do mercado internacional, causaram um grande desajuste na economia brasileira, refletido principalmente entre 1980 e 1982, com a longa recessão dos paises industrializados e o colapso do sistema internacional de crédito privado.

Conforme dados disponíveis no balanço energético nacional (Bra- 
sil, 1987), o reflexo disso foi uma alta no preço dos energéticos, havendo assim um movimento de endogenização da crise externa, através da internalização das fontes energéticas dos insumos estratégicos e dos bens de capital, dificultando, desta forma, a manutenção do mesmo ritmo de investimento do periodo anterior (1974-77).

Com o plano ortodoxo sugerido pelo FMl e apresentado pelo Governo, mudava-se quase completamente a proposta do II PND, em que o desenvolvimento se daria via estrutura produtiva e um novo patamar tecnológico, ou seja, industrialização a qualquer custo. Esta orientação do II PND é trocada por uma política que priorizava a obtenção de vantagens comparativas nos setores agrícola e mineral, portanto contrapondo-se à industrialização, e passou-se a ter um movimento de expansão das exportações primárias, a fim de se obter saldos positivos na balança comercial, e, ao mesmo tempo, se ter capacidade para importar e diminuir a importância relativa da dívida externa.

Como ilustração deste momento (1983), valeria saber que o barril de petróleo, no mercado internacional, custava $36 \%$ mais do que em 1974.

\section{2 - Efeitos Substituição}

Sabendo que o petróleo é uma fonte energética não-renovável, da qual o Brasil não produzia o necessário para auto-abastecer-se, o Governo, já com o primeiro choque do petróleo, buscou investir em fontes renováveis, alternativas ao petróleo, e na prospecção de novos poços de petróleo.

A produção petrolifera começou a crescer na década de oitenta, alcançando taxas de crescimento de $39,3 \%$ ao ano, em 1984, reduzindo, como conseqüência, $12,25 \%$ no mesmo ano o volume de suas importações, e 18,9\% no ano de 1985 (Brasil, 1987).

Houve, ao mesmo tempo, uma produção crescente de energia oriunda de outras fontes alternativas ao petróleo, bastante atrativas, como nos seguintes casos:

- Energia elétrica de fonte hidrica: era necessário gerar em um prazo mais curto, e de "forma segura", energia que substituisse o consumo de óleos combustiveis, derivados do petróleo. E a hidreletricidade mostrava-se atrativa porque é considerada energia "limpa", pois não polui, apesar de apresentar algumas "externalidades ambientais", quando são inundadas áreas próximas ao leito dos rios para formação 
de lagos-resenvatórios, além dos grandes investimentos para construção das hidrelétricas, e das redes de transmissão e distribuição.

- Pró-álcool: projeto que tem como objetivo a substituição da gasolina, contribuiu para a. substancial queda da importação líquida de petróleo e derivados entre 1979 e 1986. A participação do álcool na matriz energética em três momentos da crise energética: 1) 1975, ano em que foi criado o Pró-álcool, o petróleo representava $44,2 \%$ da matriz energética nacional, enquanto o álcool $0,4 \%$; 2) 1980, logo após o segundo choque do petróleo a participação do mesmo caiu para $40,7 \%$ e o álcool passou para $1,8 \%$; 3) 1986, mesmo com a queda dos preços do petróleo $^{12}$ sua participação na matriz energética também caju para $31,7 \%$ do total da energia consumida no pais, enquanto o álcool aumentou para $4,9 \%$.

Sem conceder ou tirar o mérito de qualquer uma das fontes energéticas que fizeram parte deste "trade-off", vale apenas dizer que estas alterações na matriz energética foram determinantes do endividamento, ocorrido na década de oitenta, que será melhor analisado a seguir.

\section{3 - Os Investimentos}

Havia necessidade, logo após o primeiro choque do petróleo, de aumentar a produção de energia, visto as necessidades das indústrias que formavam a base do II PND, que além de grandes consumidoras de óleos combustiveis eram também eletrointensivas. Por isso, o custo inicial dos investimentos era bastante elevado, dada a ação negativa do efeito-estrutura (Giambiagi 1985, p.387), uma vez que o Brasil não tinha constituido, ainda, uma base produtiva; ou seja, para alcançar uma produção de alta tecnologia o país teria que passar pela indústria de bens de produção, mais "energético-intensiva".

O pais não poderia passar por uma recessão como ocorreu na Europa, face às suas dificuldades. Segundo Castro (1985, p.29), a saida seria optar pelo financiamento ou partir para um ajustamento, e o financiamento não exigiria tamanhos sacrifícios e dificuldades para a economia adaptar-se às novas circunstâncias. No caso do financiamento, existiam recursos disponiveis no mercado internacional, como foi expresso anteriormente. Na hipótese de ajustamento, haveria necessidade de

121986 foi o ano em que o petróleo teve seu menor preço no mercado exterior, desde o primeiro choque do petróleo, segundo dados do Balanço Energético Nacional (Brasil, 1987), embora os preços dos seus derivados praticados no Brasil continuassem a subir. 
uma política monetária e outra fiscal, para desaquecer a economia e, por conseguinte, o mercado (isto dá-se através da mudança na composição dos gastos dos consumidores). Como é sabido, a saida escolhida foi o financiamento, que deu prosseguimento a proposta do II PND.

Segundo Veloso (1977, p.117): "(...) a crise do petróleo apenas tornou o programa de 1974 imperioso e inadiável", pois haveria, de qualquer modo, a necessidade de se formar uma indústria de base e dar ênfase à pesquisa de recursos naturais.

Face a esta opção pelo financiamento e não pelo ajustamento, houve criticas da possibilidade de estar-se adiando problemas, mas, pelo menos sob a ótica energética, houve, no Brasil, uma completa reestruturação do aparelho produtivo e também uma reconversão da base energética, promovidos a partir de 1974. Seria então o financiamento uma tentativa de superação desta submissão às regras externas (preço do petróleo) em vez de um caráter de climatização (ajustamento). O financiamento age sobre o capital, enquanto outras políticas (fiscal, creditícia, inflacionária) orientam o andamento deste processo proposto pelo II PND.

Lembrando que, após o equilíbrio da balança comercial, atingido em 1977/78, no ano seguinte (1979), ocorreu o segundo choque do petróleo que, combinado com a alta generalizada das taxas de juros ocasiona uma drástica diminuição da capacidade de investir, com o colapso do sistema internacional de crédito privado. Com a maxidesvalorização, em 1979, da moeda brasileira, já com um novo governo empossado, houve "depreciação monetária" das reservas e um astronômico crescimento da divida de curto prazo.

$\mathrm{Na}$ década de oitenta, estando as companhias energéticas sob o controle da União, e uma vez conhecida a situação atual do setor público, é de concluir-se que o mesmo não tem condições de endividar-se, e a capitalização, via mercado de ações, com o objetivo de obter recursos, é muito difícil nessas circunstâncias. A saída, para esse entrave, é atrair capital privado, para assim dar continuidade aos investimentos necessários ao setor energético, pode ser sim via uma política tarifária.

Segundo matéria publicada na revista Visão ((27/9/89, p.32-36), onde é exposto o levantamento feito pela Associação Brasileira de Desenvolvimento da Indústria de Base (ABDIB), foi constatado que, nos últimos nove anos, os investimentos vêm caindo no setor elétrico. Este ano não foi possível investir 3,3 bilhões de dólares, que é pouco mais do que a metade necessária para atender, a médio e longo prazo, a de- 
manda prevista. Para o Ministro das Minas e Energia, Vicente Fialho, "(...) investir, a cada ano, 6 bilhões de dólares para assegurar o equilíbrio entre oferta e demanda de energia elétrica não se pode prescindir da iniciativa privada, sobretudo num quadro de virtual insolvência do estado como grande investidor em infra-estrutura" (Visão, 27/9/89, p.35). A questão da participação do setor privado será objeto de análise mais adiante.

\section{4 - Déficit Energético}

As dificuldades das fontes energéticas em atender a demanda por energia acabam ocasionando o déficit energético. A incapacidade é fruto da escassez de recursos para investimentos, conforme as razões vistas anteriormente. Estas, por sua vez, restringem a oferta de energia o que limita a demanda pela mesma e, conseqüentemente, a atividade econômica.

O mesmo governo que adotou uma política que incentivava as indústrias siderúrgica e metalúrgica, na década de oitenta, não gerenciou bem a geração de energia. A indústria de base, que inclui a siderurgia $\mathrm{e}$ a metalurgia, é considerada altamente eletrointensiva, ou seja, possui um alto consumo de energia elétrica para obter seus produtos. Para produção de alumínio primário, por exemplo, são necessários mais de $15000 \mathrm{KWh}$ de sorte que "os países desenvolvidos, com exceção daqueles que geram energia a baixo custo como o Canadá e a Noruega, reduziram sua produção neste período e passaram a importar mais para atender suas necessidades, principalmente, dos paises subdesenvolvidos" (Ramos 1989, p.7). Ao contrário, o Brasil, no periodo de 1978-87, aumentou sua produção em quase $300 \%$, enquanto suas exportações cresceram mais de $1000 \%$. Lembrando ainda que, enquanto o setor elétrico nacional era um dos mais atingidos, o Brasil exportava aluminio, obtido com energia elétrica subsidiada. 
TABELA 2

CONSUMO DE ENERGIA, POTÊNCIA ELÉTRICA INSTALADA E INVESTIMENTO NO SETOR ELETRICO AGREGADOS ÀS EXPORTAÇÕES DE MINÉRIOS E METAIS BÁSICOS (BRASIL, 1987)

\begin{tabular}{lccc}
\hline SETOR & $\begin{array}{c}\text { ENERGIA } \\
\text { EXPORTADA } \\
\text { (GWh) }\end{array}$ & $\begin{array}{c}\text { POTENCIA ELÉTRICA } \\
\text { INSTALADA } \\
\text { (MW) }\end{array}$ & $\begin{array}{c}\text { INVESTIMENTO } \\
(\text { US 10 }\end{array}$ \\
\hline AÇO & 5000 & 1200 & 2,4 \\
FERROLIGAS & 2300 & 550 & 1,1 \\
ALUMINIO & 7300 & 1700 & 3,4 \\
SILICIO E & & 200 & 0,4 \\
ESTANHO & 900 & 1000 & 2,0 \\
MINERAÇÄO & 4000 & 4650 & 9,3 \\
TOTAL & 19500 & & \\
\hline
\end{tabular}

FONTE: RAMOS (1989)

A tabela 2 mostra o comportamento das exportações de metais básicos e do setor de mineração, atividades prioritárias no Governo Figueiredo (1979-85), que contrariam as prioridades da política adotada neste mesmo Governo, pois tais atividades geram pouco emprego e são, na maioria, poluentes. Além disso, o valor de sua produção é pequeno e exige pesados investimentos, principalmente no setor elétrico. Decorre de tudo isto que a energia é uma atividade não-rentável. ${ }^{13}$

A questão do déficit energético também é explicada pelo aspecto das tarifas, como será visto a seguir.

\section{5 - A Questão Tarifária}

O efeito-substituição decorreu da necessidade de incentivar o uso de energia elétrica em detrimento de petróleo, em razão dos choques do petróleo. O II PND incentivou a indústria, através do uso de energia

13 Pelo menos no Brasil, onde a atividade energética é concentrada na União, que a usa como instrumento para impulsionar o desenvolvimento de determinados setores económicos. 
subsidiada. Além disso, com o recrudescimento do processo inflacionário, procurou-se conter ainda mais o aumento das tarifas de produtos energéticos.

Por outro lado, a própria inflação agia como depreciadora das tarifas reais, principalmentẽ no setor elétrico, gerando o "efeito Tanzi" (Dall'Acqua, 1989, p.18). Assim, o setor passou a enfrentar sérias dificuldades, pois seus custos de geração, transmissão e distribuição não eram cobertos, descapitalizando e, conseqüentemente, inviabilizando o auto-investimento.

Pela análise dos gráficos 4 e 5, onde são comparados a evolução do preço real e o consumo de gasolina e energia elétrica, observa-se que a gasolina obteve aumentos reais até $1980,{ }^{14}$ enquanto a energia elétrica teve uma considerável baixa nos seus preços ao longo desse período. Já o consumo de gasolina baixou e o de energia elétrica aumentou, permitindo que se conclua que o baixo preço da energia incentiva seu uso "não-racional", que traz graves conseqüências à situação energética, resultando em déficit.

No entanto, visto este aumento no preço real da gasolina, não se pode afirmar que houve também "um aumento da eficiência do automóvel brasileiro (...), o que seria um caminho lógico, (...) provavelmente devido à natureza totalmente fechada da economia neste setor, em particular" (Hukai \& Christodoulou, 1989, p.8).

\section{6 - Autogeração e Co-Geração}

A privatização não pode ser entendida como uma questão de ideologia e sim de coerência. Na situação atual, como foi visto no setor elétrico, as estatais estão com seus orçamentos em déficit, sem capacidade para investir, e o capital privado só entrará na geração de energia elétrica caso seja criada uma política de tarifas reais, a fim de ter seus investimentos remunerados.

Assim, aumento real de tarifa e privatização, isoladamente, não são soluções, pois os dois setores (privado e público) devem investir juntos, uma vez que o setor público não tem condições de captar recursos, dada a atual insolvência das companhias de eletricidade e da Eletrobrás, enquanto os empresários têm interesse em investir no setor elé-

14 Entende-se por uso não racional de energia, seu uso indiscriminado, ou seja, quando o consumidor não tem consciência do custo da mesma e a usa em excesso e/ou de forma inadequada. 
trico, pois destes são os principais consumidores, desde que o capital investido seja devidamente remunerado.

Na verdade, a questão tarifária é determinante nesta situação, pois atrai o capital privado para a co-geração. Quando a Light foi estatizada, o Brasil perdeu uma fonte de pressão para o aumento das tarifas (reais), visando ao crescimento do setor.

O processo de co-geração e autogeração segue vagarosamente, enquanto a iniciativa privada fica à espera de atitudes do governo que permitam ao capital privado a participação conjunta na geração de energia, para que o colapso energético e a perspectiva de racionamento sejarn evitados ou amenizados.

\section{7 - Efeito Produto}

O efeito-produto reflete a relação existente entre o PIB e o consumo de energia, de acordo com a eficiência energética de uma determinada economia, "(...) representa a parte da queda (elevação) do consumo energético devido a uma queda (elevação) do PIB" (Giambiagi, 1985, p.387).

Portanto, a eficiência energética é uma variável a ser considerada, pois apresenta o desempenho tecnológico da economia, podendo-se concluir que a economia brasileira está distante de sua real capacidade, devido ao início tardio da produção de suas indústrias e à estrutura do mercado (Hukai e Christodoulou 1989, p.6), como foi discutido anteriormente. Mas se deve cuidar da avaliação do efeito produto, pois permanecendo o mesmo nível de eficiência energética e diminuindo a relação consumo energético/PIB, haverá uma retração na atividade econômica.

"Conforme verificou-se em quase todas as economias ocidentais industrializadas, também o Brasil conseguiu reduzir a intensidade de energia derivada do petróleo por unidade de produção. Enquanto a razão entre o PIB de 1984 e o de 1973 foi de 1,62, o consumo doméstico de derivados, no mesmo período, cresceu somente 1,13 vezes. Todavia, esta mudança de intensidade se inverte no caso da eletricidade, que, em 1984, apresentou um consumo 2,85 vezes maior que aquele de 1973. Em termos agregados, o consumo final de energia em relação ao PIB declinou, no Brasil, de 7,6 para 6,6 (tEP/Cz $\$ 10^{9}$ ), no período de $1973 / 84$, o setor industrial, que apresenta mais da metade do consumo não residencial, cresceu, no mesmo periodo, $42,7 \%$, enquanto o consumo total de energia aumentou em 59,6\%. Este aumento de intensidade 
pode ser explicado pelo uso de eletricidade que se elevou em mais de $200 \%$ naquele período, em contraste com o de derivados, onde ocorreu uma redução de mais de 20\%" (Araújo e Mota, 1989, p.6).

Segundo dados disponiveis no BEN (1987) de consumo final de energia e PIB (a preços de 1970), podemos concluir que existe forte correlação entre as duas variáveis, pois possuem um índice de 0,9917 de intensidade de variação conjunta, isto com dados do período de 1971 , até 1986 referentes ao Brasil.

\section{CONCLUSÃo}

Dada a relação, vista no item anterior (efeito produto), entre consumo de energia e PIB, pode-se concluir que a perspectiva de um colapso energético será resultado do comportamento do PIB e da variável eficiência energética, que, neste caso, representaria um novo patamar tecnológico ou a substituição na produção industrial por produtos não tão intensivos no consumo de energia.

Quanto às tarifas, estas devem ser amplamente discutidas. Tanto os setores geradores como consumidores de energia devem chegar a um "intermezzo", para que os setores de produção de energéticos tenham capacidade própria de investimento, sem a necessidade, atualmente improvável de ser satisfeita, de endividar-se junto aos credores bancários ou à União. Tarifa deve ser objeto de livre comercialização.

Com relação aos investimentos, não se pode "queimar" capital com pioneirismos impossiveis, que só funcionam à base de subsidios e políticas "surrealistas", e sim, a expansão que se deve dar espontaneamente. Deve-se começar uma obra somente com a certeza de que seu andamento não venha a sofrer nenhuma interferência, sob pena dos seus custos multiplicarem-se até o infinito, no caso da obra inacabada.

O efeito-substituição pode contribuir para a conservação de energia a partir do momento em que houver "determinada regionalização" da geração de energia, desde que isto não signifique um rompimento do sistema nacional, mas sim um aproveitamento dos recursos, reservas regionais, ou até mesmo de subprodutos da atividade econômica das regiōes (ex.: bagaço de cana, casca de arroz, etc), pois gerar energia nas proximidades também reduz custos, com as perdas no transporte (transmissão).

É muito importante, também, a idéia de integração continental, a qual visa ao intercâmbio de fontes energéticas entre paises, desde que 
estes detenham vantagens comparativas tanto na produção, como na comercialização das mesmas. Embora deva ser considerado o fato do energético ser realmente necessário, e não se fazer disso meramente acordos diplomáticos.

Finalmente, pode-se concluir que, apesar dos sucessos obtidos pelos setores de oferta de energia, é de toda conveniência que se reveja a atual estruturação face às necessidades futuras. Se era verdade que energia foi um vetor para o crescimento econômico do país, em 1959, e que se é verdade que ainda o será para algumas regiōes, também é verdade que para a região Centro-Sul, por exemplo, energia será mais um insumo que um vetor. Não se pode mais tratar a questão energética como um instrumento de política econômica, como ocorre habitualmente no que concerne a questão tarifária, onde ocorre um excessivo controle em razão do comportamento conjuntural, e sim deixá-la ajustar-se às leis de mercado, para que o setor adapta-se à realidade econômica e às necessidades do mercado, não por meio de um esforço concentrado da União, mas por todos, ou pelo menos uma parcela significativa do setor produtivo. A estrutura institucional que o setor energético irá requerer deve contemplar essa distinção. Além disso, existe grande necessidade de rever as normas legais que estruturam o setor para ajustálas à nova situação, a fim de reduzir o isolamento entre setores.

\section{BIBLIOGRAFIA}

AIE/COPPE/UFRJ. A Energia e o Desenvolvimento. Quais Desafios? Quais Métodos? Sínteses e Conclusões. Rio de Janeiro, Marco Zero, 1986.

ARAÚJO, João L. \& MOTTA, Ronaldo S. Decomposição dos Efeitos de Intensidade Energética no Setor Industrial. Pesquisa e Planejamento Econômico, v.19, n.1, p.113-32, abr. 1989, p.113-32.

BRASIL. Ministério das Minas e Energia. Balanço Energético Nacional

- 1987. Brasilia, 1987.

CALABI, Andrea S. et alii. A Energia e a Economia Brasileira. São Paulo, FIPE/Pioneira, 1983.

CASTRO, Antônio B. \& SOUZA, Francisco E.P. A Economia Brasileira em Marcha Forçada. 2 ed., Rio de Janeiro, Paz \& Terra, 1985. CHACEL, Julian. A Retomada do Crescimento e a Oferta de Energia. Trabalho apresentado no Seminário "O Panorama do Suprimento de 
Energia no Brasil nos Anos 90", realizado pela CNI. Rio de Janeiro, 19-20 outubro de 1989, Mimeo.

COMPANHIA ESTADUAL DE ENERGIA ELÉTRICA. Revisão Institucional do Setor Energético. Porto Alegre, CEEE, v. IIIA, dez. 1983.

DAL'ACQUA, Fernando M: Imposto Inflacionário: uma Análise para a Economia Brasileira. Revista de Economia Política, v.9, n.3, p.5-20, 1989.

FARIA, Flávio \& COSTA, Luís. Análise do Consumo Energético no Setor Industrial da Região Central do País. Rio de Janeiro, IPEAIINPES, 1982.

FELDENS, Aray \& LARSON, Donald. Brazilian Agriculture: Policy Objectives in Conflict. Trabalho apresentado no XX Congresso Internacional de Economistas Agrários. Buenos Aires, 24-31 de agosto de 1988, Mimeo.

FOLHA DE SÃO PAULO. Tarifa Pode Precipitar o Racionamento. São Paulo, 16 outubro 1989, p. ci.

GAZETA MERCANTIL. Relatório da Gazeta Mercantil. Energia do Sul. 16 maio 1989, p.1-12.

GIAMBIAGI, Fábio. Ajustamento Energético, Substituiçāo de Importaçōes e Endividamento Externo: uma Avaliação do Caso Brasileiro Pós-1973. In: ENCONTRO NACIONAL DE ECONOMIA, 13, Vitória, 1985. Anais... Recife, ANPEC, 1985, v.1, p.381-406.

GOLDEMBERG, José et. alii. Energia para o Desenvolvimento. São Paulo, Queiroz, 1988.

HUKAI, Roberto \& CHRISTODOULOU, Diomedes. A Racionalização dos usos da Energia e a Abertura da Economia Brasileira. TrabaIho apresentado no Seminário "O Panorama do Suprimento de Energia no Brasil nos Anos 70", realizado pela CNI. Rio de Janeiro, 19-20 de outubro de 1989. Mimeo.

MELO, Fernando $H$. \& PELIN, Eli R. As Soluções Energéticas e a Economia Brasileira. São Paulo, Hucitec, 1984.

MELLO, Túllio R. Setor Energético no ano 2000. Rio de Janeiro, APEC, 1987. (A Economia Brasileira e suas Perspectivas, n.28, p.189-92).

PROCEL. Programa Nacional de Conservação de Energia Elétrica. Manual de Conservação de Energia Elétrica. Rio de Janeiro, Procel/Eletrobrás, nov. 1988.

RAMOS, Fernando. A Crise do Setor Elétrico e a Política de Exportação de Metais Básicos. Trabalho apresentado no Seminário "O Pa- 
norama do Suprimento de Energia no Brasil nos Anos 90", realizado pela CNI. Rio de Janeiro, 19-20 de outubro de 1989. Mimeo.

ROTSTEIN, Jaime. O Consumo de Combustiveis Líquidos e a Posição Estratégica do Brasil. Rio de Janeiro, APEC, 1988. (A Economia Brasileira e suas Perspectivas, n.27, p.133-42).

SANT'ANA, Ruy Fernando. Aproveitamento Hidrelétrico de Pequeno Porte. Avaliação de Custos e Benefícios (Modelo Flash). Brasilia, Copel/Dnaee/Cehpar, 1987.

SAYAD, João. Energia e Inflação. Estudos Econômicos, v.11, n. especial, set. 1981, p.35-60.

VELlOSO, João P. dos R. Brasil: a Solução Positiva. São Paulo, Abril, 1977.

VISÃO. Energia Elétrica: Colapso nos anos 90, 27 setembro 1989, p.32-36.

WORLD BANK PAPER. Energy Efficiency in Developing Countries. New York, Dec. 1982. (UN ACC Technical Group Meeting).

\section{ABSTRACT \\ ENERGETIC DÉFICIT}

The energetic model is questioned, after the petroleum schocks. With the deep modifications in the credit international policy, another important energetic source, hidroeletricity, also begins to have problems. It is necessary to reformulate the energetic policy to end the crisis in which the country is since the end of the seventies. Thus, it is proposed, in this paper, a revision in some points of the energetic policy of the country. Amont them, the efficiency in energy consumption, the investments of the sector, the "tariffs" and the energetic regionalization and integration are stressed. 